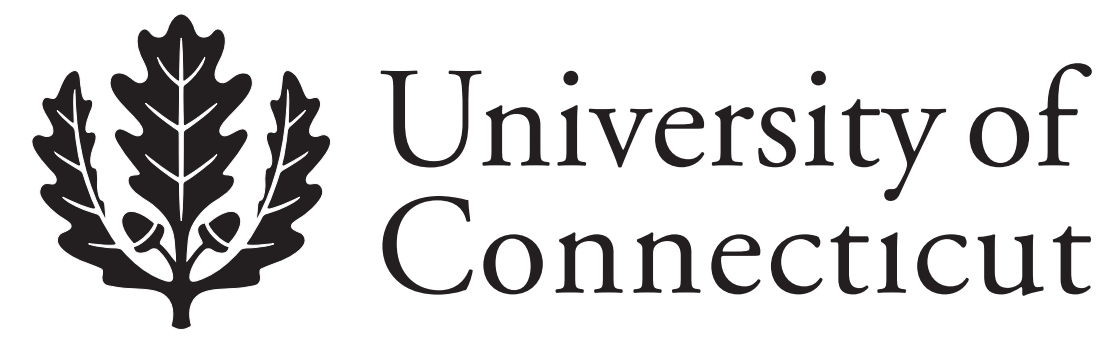

Department of Economics Working Paper Series

\title{
Environmental Policy in Majoritarian Systems
}

Per G. Fredriksson

University of Louisville

Xenia Matschke

University of Connecticut

Jenny Minier

University of Kentucky

Working Paper 2008-01

January 2008

341 Mansfield Road, Unit 1063

Storrs, CT 06269-1063

Phone: (860) 486-3022

Fax: (860) 486-4463

http://www.econ.uconn.edu/

This working paper is indexed on RePEc, http://repec.org/ 


\begin{abstract}
This paper sheds new light on the determination of environmental policies in majoritarian federal electoral systems such as the U.S., and derives implications for the environmental federalism debate on whether the national or local government should have authority over environmental policies. In majoritarian systems, where the legislature consists of geographically distinct electoral districts, the majority party (at either the national or the state level) favors its own home districts; depending on the location of polluting industries and the associated pollution damages, the majority party may therefore impose sub-optimally high or low pollution taxes due to a majority bias. We show that majority bias can influence the social-welfare ranking of alternative government policies and, in some cases, may actually bring distortionary policies closer to the first-best solution.
\end{abstract}

Journal of Economic Literature Classification: Q48, D72, D78, H20, R50

Keywords: Institutions, environmental policy, environmental federalism, geography, majority bias, political economy.

We thank Josh Ederington and the participants at a presentation at the 54th Annual North American Meetings of the Regional Science Association International in Savannah for helpful comments. 


\title{
Environmental Policy in Majoritarian Systems
}

January 2, 2008

\begin{abstract}
This paper sheds new light on the determination of environmental policies in majoritarian federal electoral systems such as the U.S., and derives implications for the environmental federalism debate on whether the national or local government should have authority over environmental policies. In majoritarian systems, where the legislature consists of geographically distinct electoral districts, the majority party (at either the national or the state level) favors its own home districts; depending on the location of polluting industries and the associated pollution damages, the majority party may therefore impose sub-optimally high or low pollution taxes due to a majority bias. We show that majority bias can influence the social-welfare ranking of alternative government policies and, in some cases, may actually bring distortionary policies closer to the first-best solution.
\end{abstract}

JEL Codes: Q48, D72, D78, H20, R50.

Key Words: Institutions, environmental policy, environmental federalism, geography, majority bias, political economy. 


\section{Introduction}

There is a long-standing debate in the economics literature about whether environmental policies should be set by local or national policy-makers (see Oates and Portney (2003) for a survey), but this “environmental federalism debate” has mainly ignored the effects of political institutions. ${ }^{1,2}$ In a majoritarian system such as the U.S., with geographically distinct electoral districts, the majority political party (whether in Congress or state-level legislatures) tends to favor the social welfare of its home districts over other districts (see Pashigian, 1986). This gives rise to a “majority bias” (see also Grossman and Helpman, 2005) at both levels of government. ${ }^{3}$ Our objective in this paper is to analyze the environmental policy effects of a majoritarian electoral system and derive implications for the environmental federalism debate.

The role of geographic location has rarely been discussed in connection with political institutions and environmental policy determination. This appears to be a serious deficiency. The political location of the polluting source and the political location of exposure to the associated pollution damage are important for understanding the design of environmental policy. For example, the U.S. steel industry is heavily concentrated in Pennsylvania, Ohio, and West Virginia. With the switch in U.S. Congressional majority party in 1994, the (Democratic) legislators from these states were no longer in the majority party; on an index of majority representation, the steel industry (SIC 3312) went from $51^{\text {st }}$ out of 415 industries in 1993 to $208^{\text {th }}$ in 1997.4 Over that same time period, the steel industry saw its pollution abatement operating costs increase by $11 \%$, relative to an overall decrease of $27 \%$ in manufacturing

\footnotetext{
${ }^{1}$ Oates (1972) established that in a federal system, policies addressing spillover effects should be centralized, whereas they should be decentralized when there is a high degree of heterogeneity in preferences.

${ }^{2}$ A recent literature discusses the role of political institutions (such as parliamentary versus presidential-congressional systems) for cross-country variations in environmental and fiscal policies (see, e.g., Fredriksson and Millimet, 2004, and Persson et al., 2000, respectively).

${ }^{3}$ Majoritarian systems such as the U.S. system are particularly grounded in local interests (Milesi-Feretti, 2002; Grossman and Helpman, 2005). Under majoritarian electoral rule with single-member districts, political parties may focus on a subset of the population rather than maximizing social welfare (Persson and Tabellini, 1999, 2003).

4 The majority representation index measures the extent to which an industry is over-represented in majority-party states relative to the population of those states; for more details on this variable and the pollution abatement cost comparison, see Appendix A.
} 
industries overall. In our view, the change from majority to minority representation may help explain this increase.

We argue in this paper that the legislative majority tends to favor industries (by formulating less stringent environmental policies) that are disproportionately located in majority party districts. This is particularly true if they emit transboundary pollution that affects primarily minority districts. ${ }^{5}$ This is true at both the federal and state level, and has important implications for the design of government policy. Cross-district uniform policies have the advantage that they limit the majority party legislators’ ability to favor their own home districts at the expense of other districts represented by the minority party. We also show that majority bias influences the social-welfare ranking of alternative policies. Although district-specific environmental taxes set by the federal government are optimal when governments maximize social welfare (accounting for both transboundary pollution and heterogeneity in pollution damage across districts), uniform federal policies across districts (states) or decentralized policies may actually be socially optimal when governments exhibit majority bias. This is due to the fact that majority bias does not necessarily decrease social welfare in the presence of distortionary government policy. Indeed, majority bias may actually provide a counterweight to inefficiencies that arise from the need for uniform taxes when taxation is centralized, or from ignoring transboundary pollution under a more decentralized tax policy.

There is indeed some empirical evidence that geographical concerns have played a role for federal environmental policies, although no theoretical underpinnings have been provided. Pashigian (1986) argues that federal air quality standards (the prevention of significant deterioration) set by the 1970 Clean Air Act and its later amendments were designed to impose high costs (and thus slow factor mobility) on the fast-growing South and West. These regions had superior air quality relative to the northern urban areas of the U.S., many of which were not directly affected by the policies. In this case,

\footnotetext{
5 The greater is the share of the sector's capital stock located in majority districts, the greater the marginal cost of raising the pollution tax from the majority legislative delegation's point of view, while the marginal benefits in terms of improved environmental quality and tax revenues remain constant.
} 
a legislative coalition was able to impose strict standards mostly at the expense of legislative minority states. 6

The theoretical political economy literature on environmental federalism is rather slim. Oates and Schwab (1988) discuss a median-voter model with decentralized policy-making, multiple jurisdictions and mobile capital, and a population of workers and non-wage-earners. Median-voter rule implies that the majority will impose its preferred policy on the minority in each jurisdiction and the resulting policy outcome is inefficient. They do not incorporate districts represented by different political parties in a legislature. Fredriksson and Gaston (2000) analyze a similar model with multiple jurisdictions and mobile capital, but where the government's policy decision is taken under the influence of worker and capital-owner lobby groups. They argue that centralized and decentralized environmental policy outcomes are equivalent, because the aggregate effects on income of environmental regulations are identical under either regulatory design. While workers carry the whole burden in the decentralized case (with capital competition), capital owners share this burden in the centralized case (without capital competition).

The paper is organized as follows: section 2 outlines the model and section 3 solves for socialwelfare maximizing policies, section 4 discusses majoritarian policy, and section 5 outlines the implications for the environmental federalism debate. Section 6 concludes.

${ }^{6}$ Ackerman and Hassler (1981) argue that early $\mathrm{SO}_{2}$ policy was a result of collaborations between producers of high sulfur coal and environmental lobby groups. This resulted in the use of scrubbers (causing a reduction of $\mathrm{SO}_{2}$ ) and high sulfur coal (raising $\mathrm{SO}_{2}$ ) from the eastern part of the U.S. The remaining empirical literature focuses on possible strategic interaction in state or national government policy-making. Murdoch et al. (1997) find free-riding among 25 European economies in voluntary sulfur and nitrogen oxide emission reductions. Sigman (2005) reports free-riding by U.S. states in water pollution management, while Sigman (2002) argues that countries also free-ride in their river pollution clean-up efforts. List and Gerking (2000) and Fomby and Lin (2006) find no environmental quality effect of President Reagan's decentralization of environmental policy-making during the 1980s, and Millimet (2003) finds no impact on abatement costs of this event. Fredriksson and Millimet (2002) find strategic interaction among U.S. states' environmental policy-making, and Fredriksson et al. (2004) suggest that this interaction may encompass several policy instruments (also non-environmental). For theoretical models studying strategic interaction in the presence of capital competition and transboundary pollution, see, for example, Rauscher (1994), Levinson (1997), Markusen et al. (1993, 1995), Glazer (1999), Ulph (2000), McAusland (2002), and Kunce and Shogren (2002, 2005). 


\section{Model}

A small open economy has individuals living in an odd number $K$ of geographically and politically separate districts. The economy has a total population normalized to unity. Each individual $i$ living in geographic district $j, j \in\{1, \ldots, K\}$, consumes $G+1$ goods and has quasi-linear preferences given by

$$
U_{j}^{i}=x_{o}^{i}+\sum_{g=1}^{G} u\left(x_{g}^{i}\right)-\sum_{k=1}^{K} \sum_{g=1}^{G} X_{k g} \theta_{g} \gamma_{k g}
$$

where $x_{o}^{i}$ represents $i$ 's consumption of the clean numeraire good $0, u($.$) is a differentiable and strictly$ concave function of consumption $x_{g}^{i}$ of polluting good $g, g \in\{1, \ldots, G\}, \quad X_{k g}$ is sector $g$ output produced in district $k, k \in\{1, \ldots, K\}$, while $\theta_{g}$ is the pollution coefficient (pollution intensity) of sector $g$ production; $\gamma_{k g j}$ is the pollution exposure intensity coefficient, which reflects the extent to which residents of district $j$ suffer from sector $g$ pollution emitted in district $k$; i.e., when $k \neq j$ it represents the degree of transboundary pollution between districts. The numeraire good has world and domestic consumer and producer price equal to unity, while good $g$ has world and domestic consumer price $p_{g}^{*}$. The legislature sets a pollution tax $t_{k g}$ in district $k$ for sector $g$, and thus district $k$ producers receive a net price in sector $g$ which equals $p_{k g}=p_{g}^{*}-t_{k g} \theta_{g}$.

Individual $i$ located in geographic district $j$ with budget $B_{j}^{i}$ spends $\sum_{g=1}^{G} p_{g}^{*} d_{g}\left(p_{g}^{*}\right)$ on nonnumeraire goods, where demand for good $g$ is given by $d_{g}\left(p_{g}^{*}\right)=\left[u^{\prime}\left(x_{g}\right)\right]^{-1}$ and where individualspecific superscripts are dropped since the consumption quantities of all non-numeraire goods and the associated consumer surplus are equal for all individuals. The remaining part of the budget is spent on numeraire good 0; this is assumed to equal a positive amount. 
The numeraire good is produced from labor only with constant returns to scale and an inputoutput coefficient equal to unity. Assuming positive production of the numeraire good yields a wage rate equal to one. Good $g \in\{1, \ldots, G\}$ production requires labor and a sector specific input. With a fixed wage rate, the aggregate factor reward for district $k$ producers in sector $g, \pi_{k g}\left(p_{k g}\right)$, depends on the producer price of good $g$ in district $k$ only. Each individual receives wage income. The consumer surplus derived from consumption of good $g$ equals $s_{g}\left(p_{g}^{*}\right) \equiv u\left[d_{g}\left(p_{g}^{*}\right)\right]-p_{g}^{*} d_{g}\left(p_{g}^{*}\right)$. Since by assumption, $p_{g}^{*}$ and thus $s_{g}$ do not depend on environmental taxes, we omit consumer surplus in the following welfare formulae. The government collects pollution tax revenue in district $k$ 's sector $g$ given by $r_{k g}\left(t_{k g}\right)=X_{k g}\left(p_{k g}\right) \theta_{g} t_{k g}$, where, by Hotelling's Lemma, $X_{k g}\left(p_{k g}\right)=\pi_{k g}^{\prime}\left(p_{k g}\right)$ is the domestic supply of good $g$ by district $k$ producers. We assume $X_{k g}{ }^{\prime}>0$ and $X_{k g}{ }^{\prime \prime}=0$. To keep things simple, we assume that capital of any sector $g$ located in district $k$ is exclusively owned by district $k$ residents; i.e., if industry $g$ earns profit $\pi_{\mathrm{kg}}$ in district $k$, this profit is received by residents of $k$.

Let $\lambda_{j}$ be the population share of district $j$ residents. The aggregate income level of district $j$ is

$$
Y_{j}=\lambda_{j}+\sum_{g=1}^{G} \pi_{j g}\left(p_{j g}\right)+\lambda_{j} \sum_{k=1}^{K} \sum_{g=1}^{G} r_{k g}\left(t_{k g}\right)
$$

where the terms on the right-hand side equal labor income, capital income, and net transfer income, respectively. It is assumed throughout that any national (or state, where applicable) government revenue is redistributed to districts according to their population share. Finally, adding disutility from pollution to (2) gives the aggregate social welfare level of residents in district $j$, equal to

$$
W_{j}=\lambda_{j}+\sum_{g=1}^{G} \pi_{j g}\left(p_{j g}\right)+\lambda_{j} \sum_{k=1}^{K} \sum_{g=1}^{G} r_{k g}\left(t_{k g}\right)-\sum_{k=1}^{K} \sum_{g=1}^{G} X_{k g}\left(p_{k g}\right) \theta_{g} \gamma_{k g} .
$$




\section{Benchmarks: Welfare Maximization in Centralized and Decentralized Systems}

In this section, we derive four basic welfare-maximizing policies. Although these have previously been shown in the literature, they serve as useful benchmarks for comparisons with the political equilibrium tax rates (discussed in Section 4 below) that usually deviate from the welfaremaximizing policies. The central government may set either (i) district-specific pollution tax rates for each sector, or (ii) a uniform sector-specific tax that applies to all districts. The district-specific central policy has two clear advantages over the other policies: namely, it can tailor taxation to the situation in a particular district and at the same time, it takes into consideration any spillover effects that production in a district can have on other districts. In a world without political distortions, this policy is clearly the first-best solution; yet, in the real world, the federal uniform policy usually prevails, based on the uniformity of standards principle. (As we discuss later, the presence of majority bias may provide an additional rationale against centralized district-specific policy.) If local differences in policies are desired, the central government can transfer the right to set policies to subnational entities, such as districts or states that then have the right to set jurisdiction-specific environmental taxes. We now derive the two centralized (federal district-specific and federal uniform) welfare-maximizing tax policies and the two decentralized (district and state uniform) welfare-maximizing tax policies, respectively.

\subsection{Welfare-Maximizing Federal Tax Policies}

We start by deriving the welfare-maximizing policy when the federal government sets districtspecific pollution tax rates for each sector $g$.

Lemma 1: The "federal welfare-maximizing district-specific tax policy" in sector $g$ for district $k$ equals

$$
t_{k g}^{0}=\sum_{j=1}^{K} \gamma_{k g j}, \quad \forall g, k .
$$


Proof: Calculating the first-order condition of the sum $\sum_{j=1}^{K} W_{j}$ from (3) by choice of $t_{k g}$, noting that $d p_{k g} / d t_{k g}=-\theta_{g}$, and solving yields (4). Q.E.D.

If the federal government can set different environmental tax rates for different districts, then the first-best optimal tax rate $t_{k g}^{0}$ for good $g$ production in district $k$ equals the sum of the transboundary pollution coefficients of district $k$ production.

A federal government may alternatively (and much more commonly) set a tax rate which applies to all districts.

Lemma 2: The “federal welfare-maximizing uniform tax policy”, $t_{g}^{f}$, equals

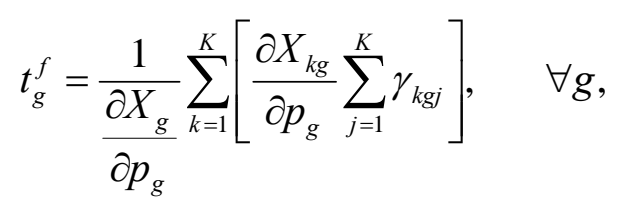

where $\frac{\partial X_{g}}{\partial p_{g}}=\sum_{k=1}^{K} \frac{\partial X_{k g}}{\partial p_{g}}$.

Proof: Maximizing the sum of (3) over all districts $j$ and restricting district tax rates to a uniform policy value $t_{g}$, we find (5). Q.E.D.

The centralized optimal tax $t_{g}^{f}$ depends on the aggregated marginal exposure to damage per unit of pollution, and cannot vary by district. Instead, the centralized optimal tax in (5) is a weighted average of the optimal rates $t_{k g}^{0}$ in (4), using as weights the relative district-level output adjustment 
$\frac{\partial X_{k g}}{\partial p_{g}} / \frac{\partial X_{g}}{\partial p_{g}}$ to net price changes. Eqn. (5) suggests that while a uniform policy takes transboundary pollution damage fully into account, it introduces distortions compared to the district-specific policy in (4). A uniform policy cannot tailor the industry tax rate by district according to district-specific variations in transboundary pollution. Thus, in sum:

Corollary 1: A federal district-specific pollution tax is weakly preferred to a federal uniform pollution tax when the federal government maximizes social welfare.

When environmental damage differs across districts, federal district-specific pollution taxes are strictly preferred to federal uniform pollution taxes; the former policies are efficient since they allow a federal government to control for both transboundary pollution and differences in environmental damage across districts. However, when environmental damage is uniform across districts (i.e., $\gamma_{k g j}=\gamma_{g}$, $\forall k, j, g)$, then federal district-specific and federal uniform policy are equivalent.

\subsection{Welfare-Maximizing Decentralized Tax Policies}

We now contrast the centralized (federal) welfare-maximizing environmental policy with its fully decentralized (district) welfare-maximizing counterpart. The local government of district $j$ maximizes

$$
W_{j}^{d}=\lambda_{j}+\sum_{g=1}^{G} \pi_{j g}\left(p_{j g}\right)+\sum_{g=1}^{G} r_{j g}\left(t_{j g}\right)-\sum_{k=1}^{K} \sum_{g=1}^{G} X_{k g}\left(p_{k g}\right) \theta_{g} \gamma_{k g}
$$

Eqn. (6) differs slightly from (3) because with decentralized decision-making, the district itself has tax authority and thus collects its own tax revenue (whereas in (3), it is assumed that the district population receives part of the centrally collected tax revenue according to population share). 
Lemma 3: District $j$ ’s “locally optimal pollution tax policy”, $t_{j g}^{d}$, equals

$$
t_{j g}^{d}=\gamma_{j g j}, \quad \forall g, j
$$

Proof. Maximizing (6) by choice of $t_{j g}^{d}$ yields (7). Q.E.D.

Eqn. (7) reveals that when policy-making is carried out at the district level, only the pollution damage affecting the district itself is addressed, and transboundary pollution is completely ignored.

Finally, we can derive the state-level welfare-maximizing policy. State $s$ sets an industry-specific environmental tax that applies to all districts located in the state. Denote the set of these districts by $S$.

Lemma 4: State $s$ ' “optimal uniform pollution tax policy”, $t_{g}^{s}$, equals

$$
t_{g}^{s}=\frac{1}{\frac{\partial X_{g}^{s}}{\partial p_{g}^{s}}} \sum_{k \in S}\left[\frac{\partial X_{k g}^{s}}{\partial p_{g}^{s}} \sum_{j \in S} \gamma_{k g j}\right], \quad \forall g, s
$$

Proof. Maximizing the sum $\sum_{j \in S} W_{j}^{d}$ from (6) by choice of a uniform tax rate $t_{g}^{s}$ yields (8). Q.E.D.

The state's optimal pollution tax differs from its federal counterpart in (5) in two respects. First, transboundary pollution outside the state is ignored, which makes the state policy inferior to the federal policy, ceteris paribus. On the other hand, provided that the price response of district output is more similar within the state than within the nation, the weighting present in (8) is less distorting than in (5).

\section{Majoritarian Politics in Centralized and Decentralized Systems}

We now drop the assumption that policy-makers maximize aggregate welfare of all districts. Instead, we assume that in a majoritarian system, the majority party in both national and state 
legislatures maximizes the welfare of the legislators' home districts only (consistent with Grossman and Helpman, 2005). Thus, effects of the majoritarian political system are present both in federal- and state-level policy-making, but absent in district-level policy-making.

Each district $j$ is represented by one single legislator who is affiliated with party $H \in\{A, B\}$, where the legislator is assumed elected with an exogenous probability 0.5 , with independence across districts. Legislators in the majority delegation care only about average citizen welfare in their home districts. The majority party is represented by at least $(K+1) / 2$ legislators in the federal (or state) legislative body, and we denote the set of majority districts by $M$. We assume that members of the same party are able to provide each other with compensation in the form of political side payments or inter-temporal trades, and hence the majority delegation maximizes its party representatives' joint welfare. Their joint welfare is given by

$$
W^{M}=\sum_{j \in M} W_{j}
$$

where $W_{j}$ is defined as in (3). The equilibrium environmental policy is determined as the policy which maximizes the majority party legislators’ joint welfare, given by (9).

\subsection{Majority Bias: Federally Set District-Specific Taxes}

To obtain a clear understanding of the effects of a majoritarian system on environmental policy, we start with the scenario that the federal government sets district-specific tax rates. Note that the optimal tax rate is then given by Lemma 1, i.e. (4). Let $\Lambda_{M}$ denote the population share of majority districts. 
Proposition 1: The "federal district-specific equilibrium tax policy" in sector $g$ in district $k$ equals

$$
t_{k g}=\underbrace{\sum_{j=1}^{K} \gamma_{k g j}}_{A} \underbrace{\frac{\delta_{k}^{M}-\Lambda_{M}}{\Lambda_{M} \theta_{g}} \frac{X_{k g}}{\partial X_{k g}}}_{B}+\underbrace{\frac{1}{\partial p_{k g}}}_{C} \underbrace{\Lambda_{M} \gamma_{j \in M} \gamma_{k j}-\sum_{j=1}^{K} \gamma_{k g j}}=\frac{1}{\Lambda_{M}} \sum_{j \in M} \gamma_{k g j}-\frac{\delta_{k}^{M}-\Lambda_{M}}{\Lambda_{M} \theta_{g}} \frac{X_{k g}}{\frac{\partial X_{k g}}{\partial p_{k g}}}, \quad \forall k, g .
$$

Proof: The federal government maximizes

$$
\Lambda_{M}+\sum_{g=1}^{G} \sum_{k \in M} \pi_{k g}\left(p_{k g}\right)+\Lambda_{M} \sum_{g=1}^{G} \sum_{k=1}^{K} r_{k g}\left(t_{k g}\right)-\sum_{k=1}^{K} \sum_{g=1}^{G} X_{k g}\left(p_{k g}\right) \theta_{g} \sum_{j \in M} \gamma_{k g}
$$

by choice of $t_{k g}$. Rearranging the first-order condition gives (10). Q.E.D.

Term $A$ in (10) equals the optimal tax rate $t_{k g}^{0}$, given by Lemma 1 . Terms $B$ and $C$ in (10) are majority bias terms and are ambiguous in sign. Term $B$ appears when the majority party has won only a subset of districts; when it has won all districts, the profit-decreasing effect and the tax-revenue increasing effect of a tax increase offset each other. ${ }^{7}$ If district $k$ is a majority district ( $\delta_{k}^{M}=1$ ), term $B$ is negative because the profit reduction of an increased tax rate would occur in a majority district, whereas only part of the tax revenue increase would go to majority districts. Term $B$ is positive if district $k$ is a minority district ( $\delta_{k}^{M}=0$ ) because in this case the government does not value district $k$ profits. The sign of term $C$ depends on both the share of the majority district population and the damage caused by transboundary pollution by industry $g$ of district $k$ in majority districts. Term $C$ increases with $(i)$ declining majority population percentage, and (ii) increasing concentration of transboundary pollution in majority districts, holding the sum of transboundary pollution coefficients constant. If both the population and transboundary pollution are concentrated in majority districts, term $C$ disappears. Finally, the right-hand side of (10) makes clear what matters to the majority party when the federal government can set district-specific taxes. When sector $g$ pollution damage does not affect

\footnotetext{
${ }^{7}$ If all districts are majority districts, maximization of majority welfare is the same as social welfare maximization, and majority bias is not an issue.
} 
majority districts, majority districts $\left(\delta_{k}^{M}=1\right)$ will see pollution subsidized, i.e. a pronounced majority bias is observed.

\subsection{Majority Bias: Federal Uniform Taxes}

In the following, let $A_{g}^{M}$ denote the share of sector $g$ production located in majority districts.

Proposition 2: The "federal uniform equilibrium tax policy" in sector g equals

$$
\begin{aligned}
& t_{g}^{f M}=\underbrace{\frac{1}{\frac{\partial X_{g}}{\partial p_{g}}} \sum_{k=1}^{K} \frac{\partial X_{k g}}{\partial p_{g}} \sum_{j=1}^{K} \gamma_{k g j}}_{A}+\underbrace{\frac{\Lambda_{M}-A_{g}^{M}}{\Lambda_{M}} \frac{X_{g}}{\theta_{g} \frac{\partial X_{g}}{\partial p_{g}}}}_{B}+\underbrace{\frac{1}{\partial X_{g}}\left[\frac{1}{\Lambda_{g}} \sum_{k=1}^{K} \frac{\partial X_{k g}}{\partial p_{g}} \sum_{j \in M} \gamma_{k g j}-\sum_{k=1}^{K} \frac{\partial X_{k g}}{\partial p_{g}} \sum_{j=1}^{K} \gamma_{k g j}\right]}_{C}= \\
& =\frac{\Lambda_{M}-A_{g}^{M}}{\Lambda_{M}} \frac{X_{g}}{\theta_{g} \frac{\partial X_{g}}{\partial p_{g}}}+\frac{1}{\frac{\partial X_{g}}{\partial p_{g}}} \frac{1}{\Lambda_{M}} \sum_{k=1}^{K} \frac{\partial X_{k g}}{\partial p_{g}} \sum_{j \in M} \gamma_{k g j}, \forall g
\end{aligned}
$$

Proof: In the political equilibrium, the uniform pollution tax policy vector maximizes

$$
\Lambda_{M}+\sum_{g=1}^{G} \sum_{k \in M} \pi_{k g}\left(p_{g}\right)+\Lambda_{M} \sum_{g=1}^{G} r_{g}\left(t_{g}\right)-\sum_{k=1}^{K} \sum_{g=1}^{G} X_{k g}\left(p_{g}\right) \theta_{g} \sum_{j \in M} \gamma_{k g}
$$

Taking the derivative of (13) with respect to $t_{g}$, we find an equilibrium characterization of the tax set in sector $g$ equal to

$$
\left(\Lambda_{M}-A_{g}^{M}\right) \theta_{g} X_{g}-\Lambda_{M} \theta_{g}^{2} \frac{\partial X_{g}}{\partial p_{g}} t_{g}+\theta_{g}^{2} \sum_{k=1}^{K} \frac{\partial X_{k g}}{\partial p_{g}} \sum_{j \in M} \gamma_{k g}=0, \quad \forall g
$$

Rearrangements yield (12). Q.E.D.

Term $A$ in (12) equals $t_{g}^{f}$, the optimal uniform tax given in (5), whereas terms $B$ and $C$ reflect forms of majority bias. In term $B$, the profit decrease of industry $g$ capital owners located in majority 
districts is compared to the tax revenue increase of these districts' population; term $B$ equals zero only in the knife-edge case when the profit share $A_{g}^{M}$ of industry $g$ capital owners in majority districts equals the population share $\Lambda_{M}$ of majority districts. Term $C$ shows that the effect of transboundary pollution on the pollution tax also depends on the population and the transboundary pollution distribution. Similarly to (11), this part of the majority bias disappears when population and pollution damage are concentrated in majority districts.

The right-hand side of (12) focuses on the net political bias components of interest. Moreover, if the majority districts are unaffected by pollution damage, the federal uniform equilibrium tax policy in sector $g$ is positive (negative) when the majority districts own a disproportionally small (large) share of the sector $g$ capital stock.

The following corollaries discuss majority bias further.

Corollary 2: The equilibrium federal uniform pollution tax in sector $g$ is decreasing in the share of sector g capital stock owned by majority districts.

Proof: Differentiation of (14) with respect to $A_{g}^{M}$ yields

$$
\frac{d t_{g}^{f M}}{d A_{g}^{M}}=\frac{X_{g}}{\left(\mathrm{~A}_{g}^{M}-2 \Lambda_{M}\right) \theta_{g} \frac{\partial X_{g}}{\partial p_{g}}} \quad \forall g
$$

where the denominator is negative since by definition, $\Lambda_{M}>0.5$ and $\mathrm{A}_{g}^{M} \leq 1$. Hence, (15) is negative. Q.E.D.

The intuition is that, ceteris paribus, the greater is the share of sector $g$ capital stock owned by majority districts, the greater is the marginal cost of raising the pollution tax to the majority legislative 
delegation (while the marginal benefits in terms of improved environmental quality and tax revenues remain constant). This helps explain the intuition behind the anecdotal evidence from the steel industry related in the introduction; an industry that is primarily located in minority districts will face more stringent regulations than other industries. ${ }^{8}$

Next, we investigate the effect of greater exposure to pollution (less absorption of pollutants).

Corollary 3: Whereas increased exposure to pollution in a majority district yields a positive pollution tax policy response, increased exposure to pollution in a minority district yields no pollution tax policy response.

Proof: Differentiation of (14) with respect to the pollution exposure coefficient, $\gamma_{k g}$, assuming district $j$ is a majority district, yields

$$
\frac{d t_{g}^{f M}}{d \gamma_{k g j}}=\frac{-\theta_{g} \frac{\partial X_{k g}}{\partial p_{g}}}{\left(\mathrm{~A}_{g}^{M}-2 \Lambda_{M}\right) \frac{\partial X_{g}}{\partial p_{g}}} \quad \forall g, k, j
$$

where the denominator is negative (as in (15)), and thus (16) is positive. Differentiation of (14) with respect to $\gamma_{k g j}$, assuming district $j$ is a minority district, yields no effect. Q.E.D.

Thus, when majority bias is present, the government reacts to an increase in pollution damage only to the extent that it affects the majority district population.

\footnotetext{
8 However, if capital shares and population are distributed proportionally across majority and minority regions, then governments will be unable to discriminate against minority districts given the constraint of federal uniformity. In that case, majority bias is not a factor affecting policy, provided there is no heterogeneity in pollution damage.
} 
Corollary 4: Majority bias may bridge the gap between the "federal welfare-maximizing districtspecific tax policy" and the actual "federal uniform equilibrium tax policy."

Proof: The optimal policy is given by $t_{k g}^{0}$ in (4), and the actual policy by $t_{g}^{f M}$ in (12) which is equal to $t_{g}^{f}$ in (5) plus the majority bias terms $B$ and $C$. Suppose that $t_{g}^{f}>t_{k g}^{0}:$ In this case, a negative term $B$ in (12), caused by a profit share of capital owners in majority districts that lies below the majority population share, and/or a negative term $C$, caused by a pollution damage mainly located in minority districts, can bring down the difference between $t_{k g}^{0}$ and $t_{g}^{f M}$. Suppose on the contrary that $t_{k g}^{0}>t_{g}^{f}:$ In this case, a positive term $B$ and/or $C$ can bridge the difference. Q.E.D.

\subsection{Majority Bias: The State Level}

We now calculate the tax rates in the political equilibrium when states set pollution taxes. If the majority party in the state legislature sets a uniform tax rate, this leads to a mix of both decentralized and centralized policy features. The resemblance to federal centralized policy arises because tax rates are uniform across districts and majority bias is potentially present. But the policy also has decentralized features, namely better tax tailoring with regard to industry characteristics within the state, and the disregard for transboundary pollution beyond state lines.

In state $s$, the state majority legislature maximizes

$$
\Lambda_{M}^{s}+\sum_{g=1}^{G} \sum_{k \in M^{s}} \pi_{k g}^{s}\left(p_{g}^{s}\right)+\Lambda_{M}^{s} \sum_{g=1}^{G} \sum_{k \in S} r_{k g}\left(t_{g}^{s}\right)-\sum_{g=1}^{G} \sum_{k \in S} X_{k g}\left(p_{g}^{s}\right) \theta_{g} \sum_{j \in M^{s}} \gamma_{k g}
$$

where production-related terms in districts outside state $s$ are omitted because the state government cannot influence them via taxation. The set $M^{s}$ consists of all majority districts of state $s$, and $\Lambda_{M}^{s}$ denotes the population share of state $s$ majority districts as percentage of the state population. We find the following result: 
Proposition 3: In a majoritarian system with state-level environmental policy-making, the uniform equilibrium pollution tax for sector $g$ in state $s$ is given by

$$
t_{g}^{M s}=\underbrace{\frac{1}{\partial X_{g}^{s}} \sum_{k \in S}\left[\frac{\partial X_{k g}^{s}}{\partial p_{g}^{s}} \sum_{j \in S} \gamma_{k g j}\right]}_{A}+\underbrace{\frac{\Lambda_{M}^{s}-A_{g}^{M s}}{\Lambda_{M}^{s}} \frac{X_{g}^{s}}{\theta_{g} \frac{\partial X_{g}^{s}}{\partial p_{g}^{s}}}}_{B}+\underbrace{\frac{1}{\partial X_{g}^{s}} \sum_{k \in S}\left[\frac{\partial X_{k g}^{s}}{\partial p_{g}^{s}}\left(\frac{1}{p_{g}^{s}} \sum_{M \in M^{s}} \gamma_{k g j}-\sum_{j \in S} \gamma_{k g j}\right)\right]}_{C} \forall s, g .
$$

Proof: The first-order condition characterizing state-level policy-making equals

$$
-A_{g}^{M s} \theta_{g} X_{g}^{s}+\Lambda_{M}^{s} \theta_{g} X_{g}^{s}-\Lambda_{M}^{s} \theta_{g}^{2} \frac{\partial X_{g}^{s}}{\partial p_{g}^{s}} t_{g}^{s}+\theta_{g}^{2} \sum_{k \in S} \frac{\partial X_{k g}^{s}}{\partial p_{g}^{s}} \sum_{j \in M^{s}} \gamma_{k g j}=0 \quad \forall s, g
$$

where $A_{g}^{M s}$ is defined as share of sector $g$ production in state $s$ located in a state majority district. Then simply solve (19) for $t_{g}^{M s}$. Q.E.D.

Clearly, the federal tax rate (12) and the state tax rate (18) are structurally similar. Both consist of the welfare-maximizing unified tax given in term $A$ and two majority bias terms $B$ and $C$. However, whereas these terms depend on the distribution of production and pollution in the federation when the policy is chosen at the federal level, they only depend on the distribution of production and pollution within the state when the environmental policy is decided at the state level. Moreover, (18) only captures transboundary pollution in majority districts in the state. Thus, ceteris paribus, the influence of transboundary pollution on the tax in (18) will be smaller than in (12), since the latter reflects all transboundary pollution affecting majority districts across the nation. Thus, free-riding problems are likely to be accentuated with decentralized majoritarian policy-making.

Finally, note that if industry location is non-uniform across states and districts, sector $g$ pollution taxes will vary (perhaps sharply) across states; this depends on the degree to which the sector $g$ capital stock is located in majority districts. State policy-making may therefore exhibit great dispersion in pollution tax rates. 


\section{Majoritarian Politics and the Environmental Federalism Debate}

\subsection{Federal Uniform vs. Federal District-Level Policy-Making}

An implication of the above analysis is that the existence of majority bias always introduces a wedge between the federal district-specific policy and the optimal policy. However, it may actually reduce the wedge between the federal uniform policy and the optimal policy. Thus in some cases, the existence of majority bias may result in the federal uniform policy being preferred to federal districtspecific policy.

In the following, we further outline this intuition (by studying the case when there are districts represented by the minority party; i.e., we do not consider here the case where all legislators are members of the majority party).

Corollary 5: In the presence of majority bias, a federal uniform pollution tax policy may be strictly preferred to a federal district-specific pollution tax policy. In particular, this is the case if pollution damage is uniform, and population and production are distributed symmetrically across all districts.

Proof: Assume that pollution damage is uniform across districts, i.e. $\gamma_{k g j}=\gamma_{g}, \forall k, g, j$. Assume further that $\Lambda_{M}=A_{g}^{M}=M / K$, where $M$ and $K$ are the number of majority districts and total number of districts, respectively; i.e., capital shares and populations are distributed proportionally across majority and minority districts. ${ }^{9}$ Then, the federal uniform tax policy, given by (12), equals $t_{g}^{f M}=\sum_{j=1}^{K} \gamma_{k g j}=K \gamma_{g}=t_{k g}^{o}$, i.e., the federal uniform tax policy is equivalent to the optimal federal districtspecific tax policy given in (4) (Lemma 1). On the other hand, the federal district-specific tax policy, given by (10), equals

\footnotetext{
${ }^{9}$ Note that this need only be true in aggregate: i.e., if the majority party represents $54 \%$ of the population, it also represents $54 \%$ of the capital stock in sector $g$.
} 


$$
t_{k g}=\frac{1}{\Lambda_{M}} \sum_{j \in M} \gamma_{k g j}-\frac{\delta_{k}^{M}-\Lambda_{M}}{\Lambda_{M} \theta_{g}} \frac{X_{k g}}{\frac{\partial X_{k g}}{\partial p_{k g}}}=K \gamma_{g}-\frac{\frac{K}{M} \delta_{k}^{M}-1}{\theta_{g}} \frac{X_{k g}}{\frac{\partial X_{k g}}{\partial p_{k g}}} \neq t_{k g}^{o},
$$

i.e. the federal district-specific tax policy is not equivalent to the optimal federal district-specific tax policy due to majority bias. Q.E.D.

In practice, federal district-specific taxes are rarely observed. This paper provides an efficiency explanation for this observation, based on the presence of majority bias in federal policy. ${ }^{10}$ As shown in Corollary 5, federal district-specific tax policy is distorted by majority bias, leading to sub-optimally high (low) pollution taxes in minority (majority) districts. However, the distortions created by majority bias are lessened by the use of a federal uniform policy. Intuitively, requiring environmental taxes to be uniform across districts places a constraint on the ability of governments to favor majority districts and punish minority districts. ${ }^{11}$ In sum, we find that when policy-making suffers from majoritarian bias, a federal uniform policy may be preferred over district-specific federal policies.

\subsection{State-Level vs. Federal Policy-Making}

Oates (1972) showed that federal uniform policies are preferred when transboundary pollution problems are present, whereas decentralized policies are preferred when pollution varies widely across districts. Decentralized policies ignore transboundary externalities, whereas federal uniform policies ignore differences in pollution creation across districts. Without majoritarian bias, federal district-level taxation combines the advantages of decentralized and centralized policy-making and is thus first-best.

\footnotetext{
10 Other explanations may include administration costs or the presence of imperfect information; this may be a topic for further research.

${ }^{11}$ Federal uniform policies may also avoid sharp policy reversals as the majority party (with different constituency districts) changes after an election loss by the incumbent party.
} 
If majoritarian bias is present, however, state-level policy-making may be actually preferred even to federal district-level policy-making as the following Corollary 6 shows.

Corollary 6: State-level environmental taxes may be strictly preferred to both uniform and districtlevel federal taxes in the presence of majority bias if the state legislature is relatively homogeneous compared to the federal legislature (meaning the degree of majority bias is small at the state level and large at the federal level) and transboundary pollution across state lines is not a major problem.

Proof: As an illustration, consider the extreme case where the environmental damage coefficient is constant across districts, i.e. $\gamma_{k g j}=\gamma_{g}, \forall k, g, j$, and there is no transboundary pollution across state lines. Assume further that all districts at the state level are majority districts, whereas there are some minority districts at the federal level. In this case, the state-level taxes given by (18) equal the federal district-specific first-best tax level in (4), whereas the district-level federal tax policy in (10) and the uniform federal tax policy in (12) are usually suboptimal since they suffer from majority bias. Q.E.D.

If states are more homogeneous than a federation as a whole, the presence of majority bias provides an additional explanation why state-level environmental policy may be preferred to federal policy.

\section{Conclusion}

Our results yield new insights applicable to the environmental federalism debate: should environmental policy be decentralized or centralized? Majority bias, favoring the current majority party legislature's home districts, affects both levels of policy-making. The degree to which majority bias drives a wedge between optimal and actual policy outcomes depends on whether factors of production and pollution damage are located in majority or minority party districts. In particular, we find a novel 
argument for uniform (across districts) federal policy-making: such policies reduce the majority legislators' ability to favor its own home districts and disfavor the districts represented by the minority party. Majority bias also affects the optimal choice between state-level and federal policy. In sum, we show that the presence of majority bias can change the ranking of government policies and, in some cases, may bring distortionary policies closer to the optimal policy.

These theoretical results may provide guidance for future empirical work on the determinants of environmental taxation in majoritarian political systems, since they suggest that empirical studies should be on the lookout for majority bias as an environmental policy determinant. 


\section{References}

Ackerman, B. and G. Hassler (1981), Clean Coal/Dirty Air, New Haven: Yale University Press.

Becker, R.A. and R.J. Shadbegian (2005), “A change of PACE: Comparing the 1994 and 1999 Pollution Abatement Costs and Expenditures surveys,” Journal of Economic and Social Measurement 30: 63-95.

Busch, M. L. and E. Reinhardt (2000), “Geography, International Trade, and Political Mobilization in U.S. Industries,” American Journal of Political Science 44(4): 703-19.

Fomby, T.B. and L. Lin (2006), “A Change Point Analysis of the Impact of "Environmental Federalism" on Aggregate Air Quality in the United States: 1940-98,” Economic Inquiry 44(1): 109-20.

Fredriksson, P.G. and N. Gaston (2000), "Environmental Governance in Federal Systems: The Effects of Capital Competition and Lobby Groups,” Economic Inquiry 38: 501-14.

Fredriksson, P.G. and D.L. Millimet (2002), “Strategic Interaction and the Determination of Environmental Policy Across U.S. States,” Journal of Urban Economics 51: 101-22.

Fredriksson, P.G., J.A. List, and D.L. Millimet (2004), “Chasing the Smokestack: Strategic Policymaking with Multiple Instruments,” Regional Science and Urban Economics 34: 387-410.

Glazer, A. (1999), “Local Regulation May Be Excessively Stringent,” Regional Science and Urban Economics 29(5): 553-58.

Grossman, G.M. and E. Helpman (2005), “A Protectionist Bias in Majoritarian Politics,” Quarterly Journal of Economics 120: 1239-82.

Hillman, A.L. and H.N. Ursprung (1992), “The Influence of Environmental Concerns on the Political Determination of Trade Policy”, Chapter 10 in The Greening of World Trade Issues, edited by K. Anderson and R. Blackhurst, Ann Arbor, University of Michigan Press and London, Harvester Wheatsheaf.

Kunce, M. and J.F. Shogren (2002), “On Environmental Federalism and Direct Emission Control,” Journal of Urban Economics 51(2): 238-45.

Kunce, M. and J.F. Shogren (2005), “On Interjurisdictional Competition and Environmental Federalism,” Journal of Environmental Economics and Management 50(1): 212-24.

Levinson, A. (1997), “A Note on Environmental Federalism: Interpreting Some Contradictory Results,” Journal of Environmental Economics and Management 33: 359-66.

List, J.A. and S. Gerking (2000), "Regulatory Federalism and Environmental Protection in the United States,” Journal of Regional Science 40: 453-71.

Markusen, J.R., E.R. Morey, and N.D. Olewiler (1993), "Environmental Policy when Market Structure and Plant Locations Are Endogenous," Journal of Environmental Economics and Management 24(1): 69-86.

Markusen, J.R., E.R. Morey, and N.D. Olewiler (1995), “Competition in Regional Environmental Policies When Plant Locations are Endogenous,” Journal of Public Economics 56: 55-77.

McAusland, C. (2002), “Cross-Hauling of Polluting Factors,” Journal of Environmental Economics and Management 44(3): 448-70. 
Milesi-Feretti, G.M., R. Perotti, and M. Rostagno (2002), “Electoral Systems and Public Spending,” Quarterly Journal of Economics 117: 609-57.

Millimet, D.L. (2003), “Assessing the Empirical Impact of Environmental Federalism,” Journal of Regional Science 43(4): 711-33.

Murdoch J.C., T. Sandler, and K. Sargent (1997), “A Tale of Two Collectives: Sulphur versus Nitrogen Oxides Emission Reduction in Europe,” Economica 64: 281-301.

Oates, W.E. (1972), Fiscal Federalism, Harourt-Brace and Jovanovich, New York, NY.

Oates, W.E. and P.R. Portney (2003), “The Political Economy of Environmental Policy,” in K.-G. Mäler and J.R. Vincent, Handbook of Environmental Economics, Vol. 1, Elsevier, Amsterdam.

Oates, W.E., and R.M. Schwab (1988), "Economic Competition Among Jurisdictions: Efficiency Enhancing or Distortion Inducing?” Journal of Public Economics 35(3): 333-54.

Pashigian, B.P. (1986), “Environmental Regulation: Whose Self-Interests Are Being Protected?” Economic Inquiry 23(4): 551-84.

Persson, T., Roland, G., and Tabellini, G. (2000), “Comparative Politics and Public Finance,” Journal of Political Economy 108: 1121-61.

Persson, T. and G. Tabellini (1999), “The Size and Scope of Government: Comparative Politics with Rational Politicians,” European Economic Review 43: 699-735.

Persson, T. and G. Tabellini (2003), The Economic Effects of Constitutions, Munich Lectures in Economics, MIT Press, Cambridge, MA.

Sigman, H. (2002), “International Spillovers and Water Quality in Rivers: Do Countries Free Ride?” American Economic Review 92(4): 1152-59.

Sigman, H. (2005), “Transboundary Spillovers and Decentralization of Environmental Policies”, Journal of Environmental Economics and Management 50: 82-101.

Ulph, A. (2000), "Harmonization and Optimal Environmental Policy in a Federal System with Asymmetric Information,” Journal of Environmental Economics and Management 39: 224-41. 


\section{Appendix A}

\section{A.1 Majority Representation Variable}

We constructed a variable measuring the extent of each industry's majority representation as follows. For each state, the difference between the percentage of industry employment located in that state and the population share of that state is computed.

For industry employment, we used County Business Patterns, which gives employment by 4digit SIC for each state. Since many observations are censored, it also gives the number of establishments in various size classes. These data are also available at the national level (with far fewer censored observations). Following Busch and Reinhardt (2000), we compute the mean establishment size at the national level for each size class. We then estimate total employment in the industry for each state using the national industry average for each size class, and the number of firms in each size class by state. Note that, following Busch and Reinhardt, we use the imputed data even when the actual data are not censored. The percentage of industry employment in each state is estimated using the sum across states as the denominator (so that the percentages sum to one for each industry).

To construct the index, we then sum this measure over only those states in which more than $50 \%$ of the House delegation is in the majority party.

Although the pollution abatement costs (see section A.2 below) are available for 1994 and 1999, we use majority representation for 1993 and 1997 due to lags in the setting of policy.

\section{A.2 Environmental Stringency Variable}

The pollution abatement costs for the steel industry are from Becker and Shadbegian (2005), page 85. Note that the standard measure of environmental policy stringency at the industry level (the "Pollution Abatement Costs and Expenditures" survey) was discontinued in 1994, and reintroduced in a significantly revised form in 1999. The steel industry is one of the few industries that maps easily from 1994 to 1999 . The estimate of a $27 \%$ decline in pollution abatement operating costs across all manufacturing industries is from Becker and Shadbegian (2005). 